Corresponding author: twmfan@ gmail.com

(c) 2016 Fan et al. This article is distributed under the terms of the Creative Commons Attribution-NonCommercial License, which permits reuse and redistribution, except for commercial purposes, provided that the original author and source are credited.

Ontology terms: immune dysregulation; increased inflammatory response; neoplasm of the lung; progressive pulmonary function impairment

Published by Cold Spring Harbor Laboratory Press

doi: 10.1101/mcs.a000893

\section{Distinctly perturbed metabolic networks underlie differential tumor tissue damages induced by immune modulator $\beta$-glucan in a two-case ex vivo non-small-cell lung cancer study}

\author{
Teresa W.-M. Fan, ${ }^{1}$ Marc O. Warmoes, ${ }^{1}$ Qiushi Sun, ${ }^{1}$ Huan Song, ${ }^{1}$ \\ Jadwiga Turchan-Cholewo, ${ }^{1}$ Jeremiah T. Martin, ${ }^{2}$ Angela Mahan, ${ }^{2}$ \\ Richard M. Higashi, ${ }^{1}$ and Andrew N. Lane ${ }^{1}$ \\ ${ }^{1}$ Center for Environmental and Systems Biochemistry, Department of Toxicology and Cancer Biology \\ and Markey Cancer Center, University of Kentucky, Lexington, Kentucky 40536, USA; ${ }^{2}$ Department of Surgery \\ and Markey Cancer Center, University of Kentucky, Lexington, Kentucky 40536, USA
}

\begin{abstract}
Cancer and stromal cell metabolism is important for understanding tumor development, which highly depends on the tumor microenvironment (TME). Cell or animal models cannot recapitulate the human TME. We have developed an ex vivo paired cancerous (CA) and noncancerous (NC) human lung tissue approach to explore cancer and stromal cell metabolism in the native human TME. This approach enabled full control of experimental parameters and acquisition of individual patient's target tissue response to therapeutic agents while eliminating interferences from genetic and physiological variations. In this two-case study of non-small-cell lung cancer, we performed stable isotope-resolved metabolomic (SIRM) experiments on paired CA and NC lung tissues treated with a macrophage activator $\beta$-glucan and ${ }^{13} \mathrm{C}_{6}$-glucose, followed by ion chromatography-Fourier transform mass spectrometry (IC-FTMS) and nuclear magnetic resonance (NMR) analyses of ${ }^{13} \mathrm{C}$-labeling patterns of metabolites. We demonstrated that CA lung tissue slices were metabolically more active than their NC counterparts, which recapitulated the metabolic reprogramming in CA lung tissues observed in vivo. We showed $\beta$-glucan-enhanced glycolysis, Krebs cycle, pentose phosphate pathway, antioxidant production, and itaconate buildup in patient UK021 with chronic obstructive pulmonary disease (COPD) and an abundance of tumor-associated macrophages (TAMs) but not in UKO49 with no COPD and much less macrophage infiltration. This metabolic response of UK021 tissues was accompanied by reduced mitotic index, increased necrosis, and enhaced inducible nitric oxide synthase (iNOS) expression. We surmise that the reprogrammed networks could reflect $\beta$-glucan M1 polarization of human macrophages. This case study presents a unique opportunity for investigating metabolic responses of human macrophages to immune modulators in their native microenvironment on an individual patient basis.
\end{abstract}

[Supplemental material is available for this article.]

\section{INTRODUCTION}

In the past several years, there has been rekindled interest in cancer metabolism as an important component of cancer progression and survival, which has led to the discovery of many 
novel aspects of metabolic reprogramming in cancer cells, far beyond the enhanced aerobic glycolysis originally described by Warburg (1956). Metabolic reprogramming is a hallmark of cancer (Hanahan and Weinberg 2011) and is important for promoting all stages of cancer cell development, such as growth, survival, and metastasis (Yuneva et al. 2007; Dang et al. 2009; Nomura et al. 2010; Cheng et al. 2011; Le et al. 2012; Mullen et al. 2012; Faubert et al. 2013; Son et al. 2013; Xie et al. 2014; Kim et al. 2015; Sellers et al. 2015). Altered cancer cell metabolism has also been implicated in modulating the cancer cell's interaction with tumor microenvironment (TME) to enable its escape from immune surveillance (Zamanakou et al. 2007; Ho et al. 2015) and to promote tumor progression, survival, metastasis, and angiogenesis (Stern et al. 2002; Walenta et al. 2004; Sonveaux et al. 2008; Wysoczynski and Ratajczak 2009; Bonuccelli et al. 2010; Hanahan and Weinberg 2011; Guillaumond et al. 2013; Caneba et al. 2014; Leithner et al. 2014; Thayanithy et al. 2014). However, with a few exceptions (Fan et al. 2009; Maher et al. 2012; Sellers et al. 2015), the majority of human cancer metabolic studies have been conducted in two-dimensional (2D) cell culture systems or in mouse xenografts, which lack the native 3D architecture of human TME, and therefore cannot recapitulate the altered metabolic networks that are induced by interactions of cancer cells with their stroma. Consideration of such interactions is essential to both fundamental understanding of tumor metabolism and clinical translation of such understanding into diagnostic and therapeutic benefits (Sellers et al. 2015).

We and others have recently demonstrated the feasibility of interrogating tumor metabolism in vivo in human patients using a combination of stable isotope tracers and metabolomic analyses (Fan et al. 2009; Maher et al. 2012; Sellers et al. 2015). Our studies uncovered novel metabolic reprogramming events and activation of anaplerotic pyruvate carboxylase, in particular, in human lung cancer, which is important for supporting lung cancer cell growth both in vitro and in vivo (Sellers et al. 2015). However, experimentation on human subjects is very limited in terms of experimental design and treatment options including tracer use or therapeutic agents.

To circumvent these issues, we have extended the ex vivo tissue slice approach pioneered by Warburg (1924) for interrogating large-scale metabolic responses of human non-small-cell lung cancer (NSCLC) tissues (Xie et al. 2014; Sellers et al. 2015; Fan et al. 2016) to an immune modulator, $\beta$-glucan. We have shown that this particulate yeast-derived polysaccharide can polarize alternatively activated (M2) or immunosuppressive macrophages to the classical M1 immunoactivating phenotype in mouse models, leading to reduced tumor burden (Liu et al. 2015). This approach has the advantages of (1) maintaining the native human tissue 3D architecture of TME; (2) flexibility of tracer use and treatment options; (3) delineation of target tissue responses without systemic influences; (4) complete experimental control of the environment including nutrient supply; (5) circumvention of genetic, physiologic, and environmental complications in elucidating treatment responses by adopting the paired cancerous (CA) and surrounding noncancerous (NC) tissue design; and (6) the ability to determine treatment effects on target tissues on an individual patient basis.

In this study, we describe ex vivo stable isotope resolved metabolomics (SIRM) studies utilizing ${ }^{13} \mathrm{C}_{6}$-glucose as tracer and $\beta$-glucan as an anticancer treatment on fresh lung tissue slices from two NSCLC patients. We found opposite metabolic network responses to $\beta$-glucan in the CA lung tissue slices for these two patients, which were accompanied by distinct histologic and immunohistochemical changes in terms of necrosis, mitotic index, and the expression of inducible nitric oxide synthase (iNOS, marker of M1-like macrophages). In particular, the enhanced aerobic glycolysis, Krebs cycle, antioxidant production, and itaconate buildup is consistent with macrophage polarization toward the M1 type by $\beta$-glucan in reference to animal studies (Rodríguez-Prados et al. 2010; Tannahill et al. 2013) in one patient with chronic obstructive pulmonary disease (COPD) but not in the other without COPD. 


\section{RESULTS}

\section{Clinical Presentation, Patient History, and Molecular Pathology}

The lung tumor characteristics, patient demographics, and smoking/health history are listed in Table 1. The histopathological properties of the CA and surrounding NC lung tissues (proximal and distal to the tumor margin) for two patients are illustrated in Supplemental Figure S1, where both tissues of patient UK021 were more fibrotic than those of patient UK049. Immunofluorescent staining for mitotic index (PCNA [proliferating cell nuclear antigen]) and necrosis (RIP-1) indicated that the UK021 tissues were less proliferative and more necrotic (Fig. 1A,B). Immunofluorescent staining for resident macrophages (CD68) indicated their higher abundance in UK021 than UK049 lung tissues (Fig. 1C,D), which confirmed the hematoxylin and eosin (H\&E) staining data (Supplemental Fig. S1A). Double immunofluorescent staining of iNOS and CD68 provided a measure of iNOS expression (marker of M1-like macrophages) normalized to the abundance of $\mathrm{CD} 68^{+}$macrophages. This ratio was lower for UK021 than for UK049 CA lung tissues (Fig. 1C,D), which could reflect a less M1-like phenotype of tumor-associated macrophages (TAMs) in the former tissue. All of these histopathological differences could be related to the COPD that UK021 had suffered but not UK049.

\section{UK021 but Not UK049 Tumor Tissue Slices Exhibited Accelerated Glycolysis and Glutathione Synthesis in Response to $\beta$-Glucan Treatment}

When UK021 CA tissue slices were treated with or without WGP (whole glucan particle) $\beta$-glucan in the presence of ${ }^{13} \mathrm{C}_{6}$-glucose (Glc), an enhanced level of ${ }^{13} \mathrm{C}_{3}$-lactate was observed in both intracelluar (Fig. 2D) and extracellular compartments (Supplemental Fig. S2) for the WGP compared with the control treatments. This, together with the increased production of ${ }^{13} \mathrm{C}_{6}$-fructose-1,6-bisphosphate (Fig. 2B) and ${ }^{13} \mathrm{C}_{3}$-pyruvate (Fig. 2C), pointed to accelerated glycolysis under normoxia in UK021 CA tissue slices in response to WGP. In contrast, UK049 CA tissue slices responded to WGP with diminished aerobic glycolysis, as evidenced by the attenuated release of ${ }^{13} \mathrm{C}_{3}$-lactate into the medium (Supplemental Fig. S2) and decreased production of ${ }^{13} \mathrm{C}_{3}$-pyruvate (Fig. 3C). The decreased buildup of ${ }^{13} \mathrm{C}$-glucose in UK021 but not in UK049 CA tissue slices is further consistent with increased glucose metabolism into lactate in the former case (Figs. 2 and 3).

Table 1. Clinical attributes and demographics of the two non-small-cell lung cancer (NSCLC) patients who consented for the ex vivo studies

\begin{tabular}{lcc}
\hline Patient \# & UK021 & UK049 \\
\hline Tumor type & Poorly differentiated adenocarcinoma & Moderately differentiated adenocarcinoma \\
Tumor size & $3.8 \times 2.6 \times 2.5 \mathrm{~cm}$ & $9 \times 8 \times 5 \mathrm{~cm}$ \\
TNM staging (pathology) & $\mathrm{T}_{3} \mathrm{~N}_{0} \mathrm{M}_{0}$ & $\mathrm{~T}_{3} \mathrm{~N}_{0} \mathrm{M}_{0}$ \\
Overall stage & IIB & IIB \\
Tumor grade & 3 & 2 \\
Tumor PET SUV & 15.4 & Not available \\
FEV1/FVC ratio & 86 & 72 \\
Gender & $\mathrm{F}$ & $\mathrm{M}$ \\
Age & 42 & 76 \\
Ethnicity & White & White \\
Other health issues & COPD , hypercholesterolemia & None \\
Smoking history (pack years) & 20 & 50 \\
\hline
\end{tabular}

PET, positron emission tomography; SUV, standardized uptake value; FEV1/FVC ratio, forced expiratory volume 1/forced vital capacity; COPD, chronic obstructive pulmonary disease. 


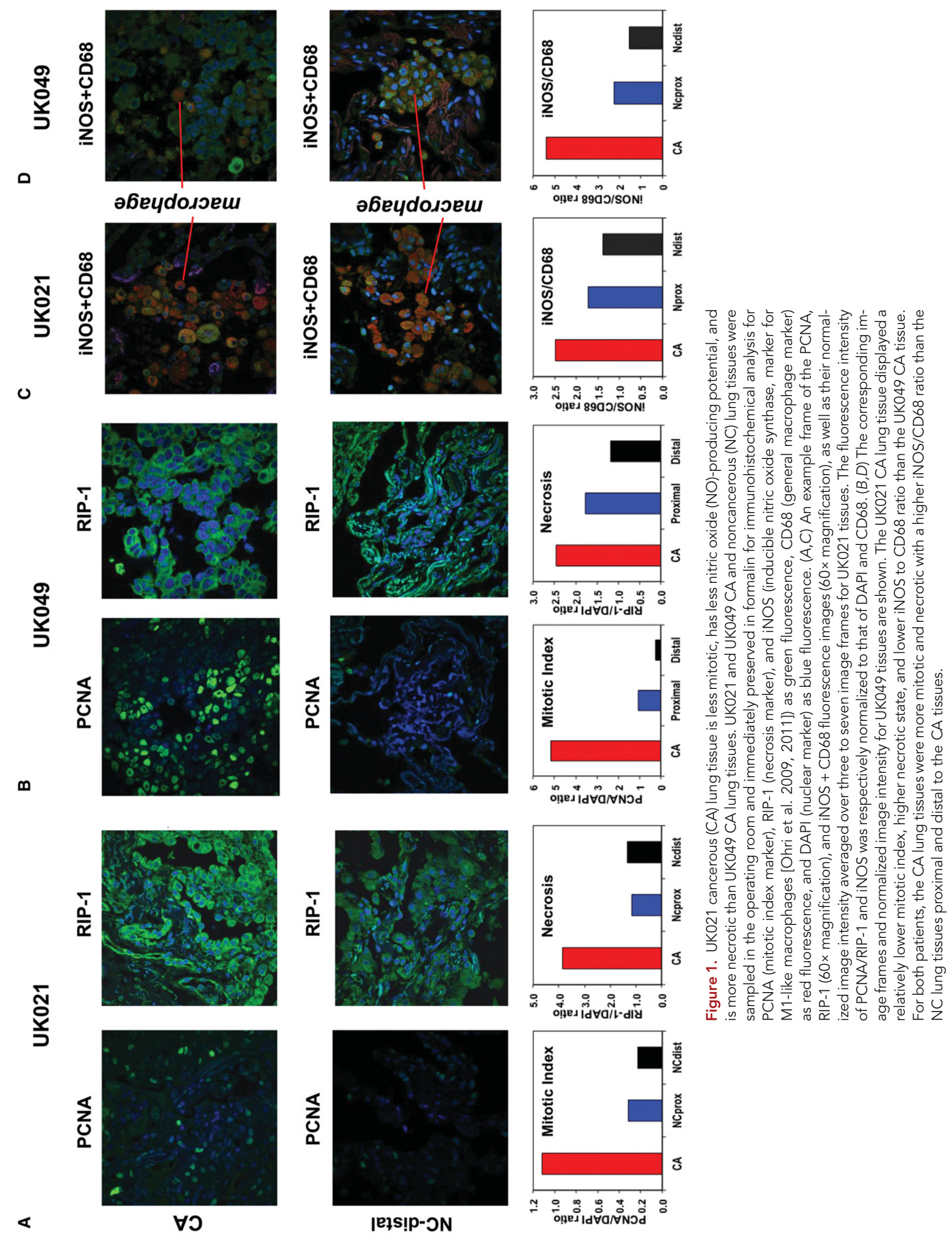




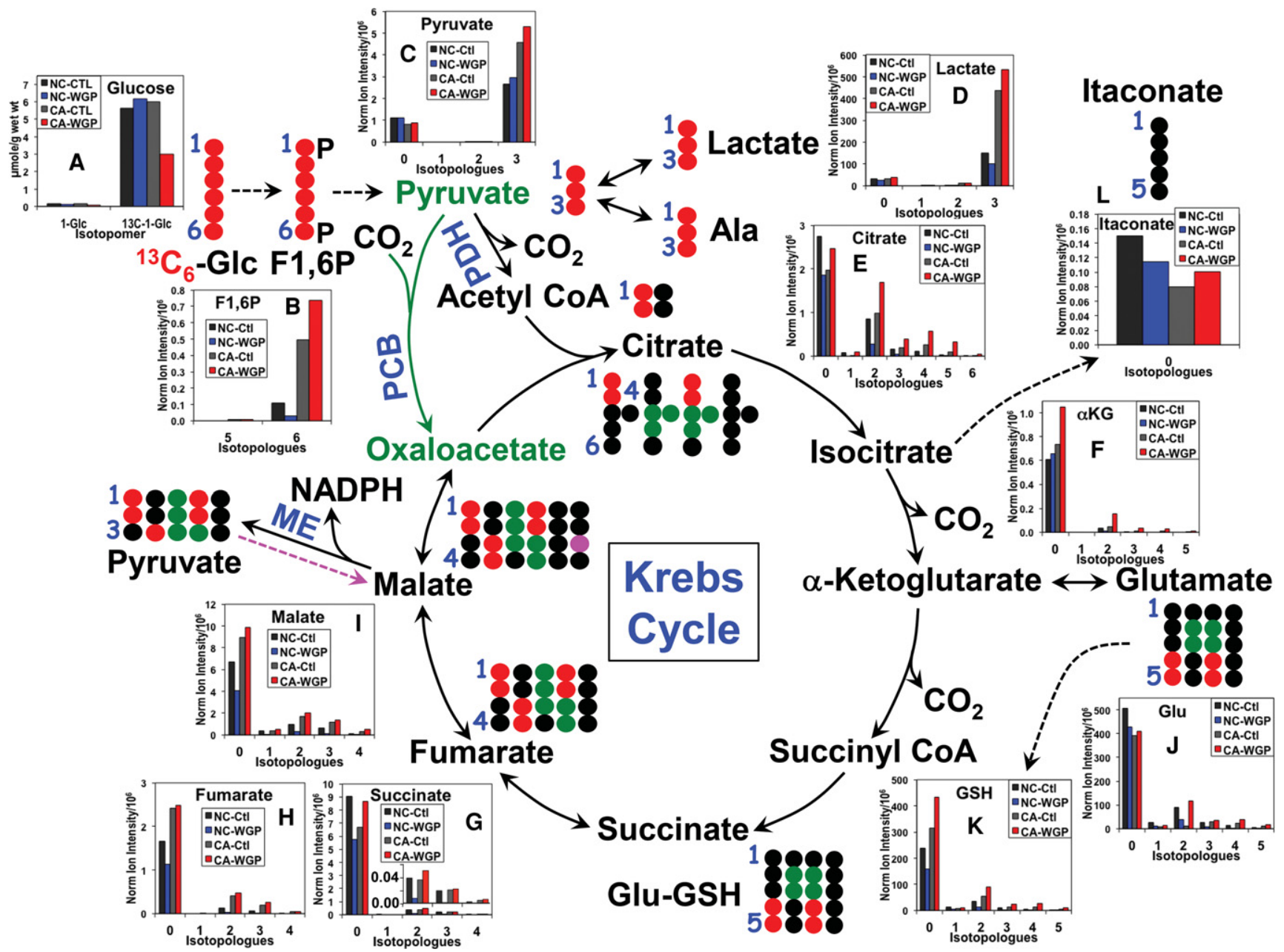

Figure 2. $\beta$-Glucan enhances glycolysis, Krebs cycle, and glutathione synthesis in UK021 CA tissue slices. Slices of freshly resected UK021 CA and NC lung tissues were treated with 0 or $100 \mu \mathrm{g} / \mathrm{mL}$ whole glucan particle (WGP) for $24 \mathrm{~h}$ in the presence of ${ }^{13} \mathrm{C}_{6}$-glucose (Glc) with $n=1$ for each treatment because of limited tissue availability. Tissue slices were processed, extracted for polar metabolites, and analyzed by ion chromatography-Fourier transform mass spectrometry (IC-FTMS), as described in Methods. The ${ }^{12} \mathrm{C}(0)$ and ${ }^{13} \mathrm{C}(1-5)$ isotopologues of glycolytic, Krebs cycle, and glutathione (GSH) synthesis pathway metabolites are shown as bar graphs in A-l along with the atom-resolved tracing of these pathways. Not all possible ${ }^{13} \mathrm{C}$ isotopologues are shown. PDH, pyruvate dehydrogenase; $\mathrm{PCB}$, pyruvate carboxylase; $\mathrm{ME}, \mathrm{NADP}^{+}$-dependent malic enzyme; F1,6P, fructose-1,6-bisphosphate; $\bullet,{ }^{12} \mathrm{C} ; \bullet, \bullet, \bullet,{ }^{13} \mathrm{C}$ derived from PDH-, PCB-, and ME-mediated Krebs cycle reactions, respectively. In the WGP-treated CA tissue slice, accelerated glycolysis, Krebs cycle, and GSH synthesis were evident, respectively, from the accumulation of ${ }^{13} \mathrm{C}_{6}-\mathrm{F} 1,6 \mathrm{P}(B) /{ }^{13} \mathrm{C}_{3}$-pyruvate $(C) /{ }^{13} \mathrm{C}_{3}$-lactate $(D) /$ medium ${ }^{13} \mathrm{C}_{3}$-lactate (cf. Supplemental Fig. S2), ${ }^{13} \mathrm{C}$-citrate $(E) /{ }^{13} \mathrm{C}$-aketoglutarate $(a K G, F) /{ }^{13} \mathrm{C}$-succinate, and ${ }^{13} \mathrm{C}-\mathrm{Glu}(\mathrm{J}){ }^{13} \mathrm{C}-\mathrm{GSH}(\mathrm{K})$, as compared with control (Ctl) CA tissues. In contrast, the response of these metabolites in the NC tissue slice to WGP was opposite to that in the CA tissue slice.

WGP-treated UK021 CA tissue slice also showed enhanced oxidation of ${ }^{13} \mathrm{C}_{3}$-pyruvate via the first part of the Krebs cycle, as evidenced by the increased production of ${ }^{13} \mathrm{C}$-citrate (Fig. 2E) and a-ketoglutarate (aKG, Fig. 2F), relative to the control (Ctl) tissue slice. A major fraction of this enhanced Krebs cycle flow appeared to be diverted to the synthesis of ${ }^{13} \mathrm{C}$ Glu (Fig. 2J) and then ${ }^{13} \mathrm{C}$-glutathione (GSH) (Fig. 2K). This was not the case for the WGPtreated UK049 CA tissue slices. Although ${ }^{13} \mathrm{C}$-citrate synthesis was elevated, the subsequent 


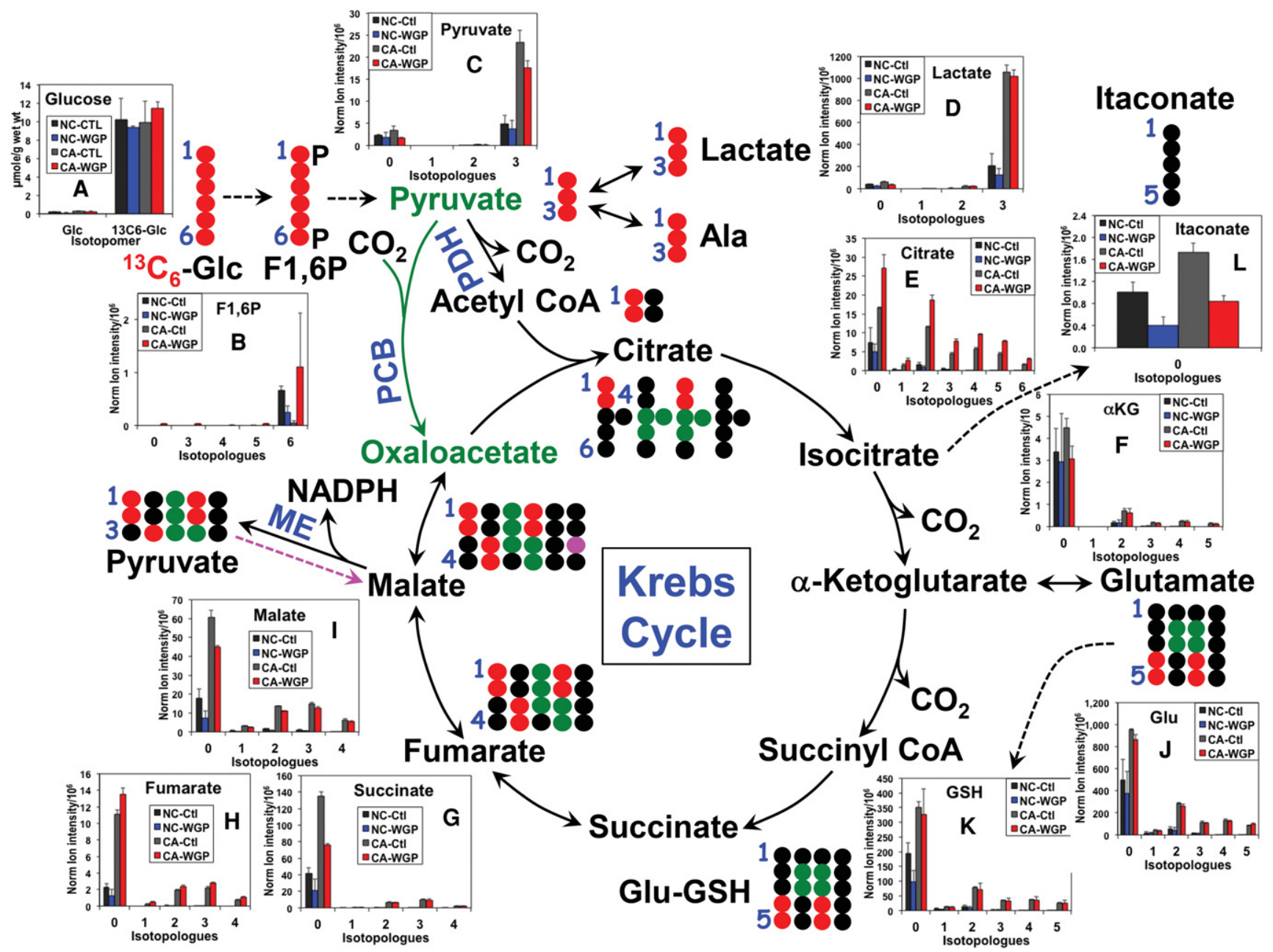

Figure 3. $\beta$-Glucan does not alter Krebs cycle and glutathione synthesis while attenuating glycolysis in UK049 CA tissue slices. Tissue slice treatment, extraction, and analysis, as well as abbreviations and symbols used, were as described in Figure 2, except that $n=2$ for each treatment (control vs. WGP). Each value was an average of two replicates with the error bars as standard errors of the mean. The decreased production of tissue ${ }^{13} \mathrm{C}_{3}$-pyruvate $(\mathrm{C})$ and rate of ${ }^{13} \mathrm{C}_{3}$-lactate release into the medium (cf. Supplemental Fig. S2) in CA tissue slices in response to WGP is consistent with attenuated glycolysis. In addition, the lack of buildup in ${ }^{13} \mathrm{C}-\alpha \mathrm{KG}(F)$ / ${ }^{13} \mathrm{C}$-succinate $/{ }^{13} \mathrm{C}$-fumarate $/{ }^{13} \mathrm{C}$-malate $/{ }^{13} \mathrm{C}$-Glu $/{ }^{13} \mathrm{C}$-GSH indicates lack of stimulation of the Krebs cycle and GSH synthesis in CA tissue slices by WGP. However, WGP elicited ${ }^{13} \mathrm{C}$-citrate accumulation in CA tissue slices, similar to the UK021 case, which points to a specific effect on citrate metabolism via citrate synthase and/or aconitase/isocitrate dehydrogenase. The ${ }^{13} \mathrm{C}$ enrichment of the corresponding metabolites responded negatively to WGP in NC tissue slices.

flow through the Krebs cycle and the Glu-GSH pathway did not change in these tissue slices, relative to the Ctl tissue slices (Fig. 3E,F,J,K).

UK021 but Not UK049 Tumor Tissues Display Elevated PPP and Malic Enzyme Activity While Producing More NADPH and Macrophage Metabolite Itaconate in Response to $\beta$-Glucan Treatment

The two sets of CA tissue slices also showed opposite response to WGP in terms of the itaconate level (Figs. 2L, 3L) (i.e., itaconate accumulated in the UK021 but was depleted in 
the UK049 CA tissue slices). Itaconate synthesis from glucose via decarboxylation of the Krebs cycle intermediate cis-aconitate is known to be induced in murine macrophages to activate immunoactive M1 phenotypes in response to lipopolysaccharide and IFN- $\gamma$ stimulation (Strelko et al. 2011; Michelucci et al. 2013). However, no ${ }^{13} \mathrm{C}$-labeled itaconate was evident in any of the tissue slices incubated in ${ }^{13} \mathrm{C}_{6}$-glucose, despite the high level of ${ }^{13} \mathrm{C}$ enrichment in the citrate precursor (Figs. 2E, 3E). As itaconate is reportedly not produced by lung cancer cells (Michelucci et al. 2013), changes in itaconate levels could reflect metabolism in resident lung macrophages in these tissue slices. If so, our results suggest that itaconate metabolism in human lung macrophages is distinct from that in murine macrophages. The data also support the notion that UK021 CA tissues respond to WGP by undergoing the M2 to M1 polarization of resident macrophages, whereas UK049 tissues fail to do so.

Because NADPH metabolism is crucially important to the differentiation and killing action of M1 macrophages via NADPH oxidase activity (Benoit et al. 2008; Michelucci et al. 2013; Graham et al. 2015), we also examined the total level and ${ }^{13} \mathrm{C}$-labeling pattern of NADPH in both UK021 and UK049 tissue slices. As shown in Figure 4C, the total level of NADPH was elevated in UK021 but not in UK049 CA tissue slices in response to WGP, which can be largely attributed to the enhanced synthesis of NADPH from glucose via the salvage pathway (Belenky et al. 2007; Muller and Prendergast 2007). This is evidenced by the predominance of ${ }^{13} \mathrm{C}$-ribose labeling in $\mathrm{NADPH}$ and the enhancement of this labeling in UK021 (Fig. 4C) but not UK049 CA tissue slices under WGP treatment (Fig. 5C) (cf. also Supplemental Figure $\mathrm{S} 3$ vs. S4 for ${ }^{13} \mathrm{C}-\mathrm{N} 1^{\prime}$-ribose of $\mathrm{NAD}^{+}$). In addition, the hydride sources of NADPH for sustaining superoxide and NO production involved in the killing action of M1 macrophages include the malic enzyme (ME) reaction and the pentose phosphate pathway (PPP) (Ghesquiere et al. 2014). ${ }^{13} \mathrm{C}_{6}$-glucose flow through the PPP was substantially enhanced in UK021 CA tissue slices by WGP, as evidenced by the increased production of many ${ }^{13} \mathrm{C}$-labeled PPP intermediates (Fig. 4D-G), particularly sedoheptulose-7-phosphate (Sed7P, Fig. 4E), which is unique to PPP. Although some of the PPP intermediates had a higher level of ${ }^{13} \mathrm{C}$ enrichment in WGP-treated UK049 CA tissue slices (Fig. 5D,F), the ${ }^{13} \mathrm{C}$ enrichment patterns in Sed7P in these slices did not respond to WGP (Fig. 5E). We also noted that other than the dominant ${ }^{13} \mathrm{C}_{7}$-isotopologue of Sed7P, the ${ }^{13} \mathrm{C}_{2}$ - and ${ }^{13} \mathrm{C}_{5}$-species were present in appreciable amounts in both sets of tissue slices, which presumably arose from reaction of ${ }^{13} \mathrm{C}$-enriched intermediates with unlabeled intermediates, either preexisting or derived from an alternative source such as glycogen. All three ${ }^{13} \mathrm{C}$-isotopologues of Sed7P can be produced via the oxidative and/or nonoxidative branches of PPP. However, the absence of ${ }^{13} \mathrm{C}_{1}$ - and ${ }^{13} \mathrm{C}_{3}$-species, produced via the transaldolase (TA) reaction in the nonoxidative branch of PPP (denoted by green lines in Figs. 4 and 5), suggests that the oxidative PPP predominates in human lung CA tissue slices. Thus, the heightened PPP activity induced by WGP in UK021 CA tissue slices supplied, at least in part, the hydride for elevated NADPH production, whereas WGP had little effect on both PPP activity and NADPH generation in UK049 CA tissue slices.

NADPH production via the ME reaction appeared also to occur in both CA tissue slices, as evidenced by the presence of ${ }^{13} \mathrm{C}_{1}$-malate (magenta ${ }^{13} \mathrm{C}$; Figs. 2I, 3I). The predominant and perhaps the only path for the synthesis of ${ }^{13} \mathrm{C}_{1}$-malate from ${ }^{13} \mathrm{C}_{6}$-glucose is via the reaction sequence of pyruvate dehydrogenase (PDH)-initiated (canonical) Krebs cycle, ME, and pyruvate carboxylase (PCB) reaction (denoted by dashed magenta arrow, Figs. 2 and 3). PCB is active in both UK021 and UK049 CA tissue slices, as evidenced by their significant buildup of ${ }^{13} \mathrm{C}_{3}$ - and ${ }^{13} \mathrm{C}_{5}$-citrate (Figs. 2E and $3 \mathrm{E}$ ). Alternatively, the ${ }^{13} \mathrm{C}_{1}$-pyruvate product of $\mathrm{ME}$ can generate ${ }^{13} \mathrm{C}_{1}$-acetyl CoA, which reacts with unlabeled oxaloacetate (OAA), and undergo the rest of the Krebs cycle again to produce ${ }^{13} \mathrm{C}_{1}$-malate. Although the effect was small, WGP induced ${ }^{13} \mathrm{C}_{1}$-malate production in UK021 CA tissue slices (Fig. 2I) but attenuated it 


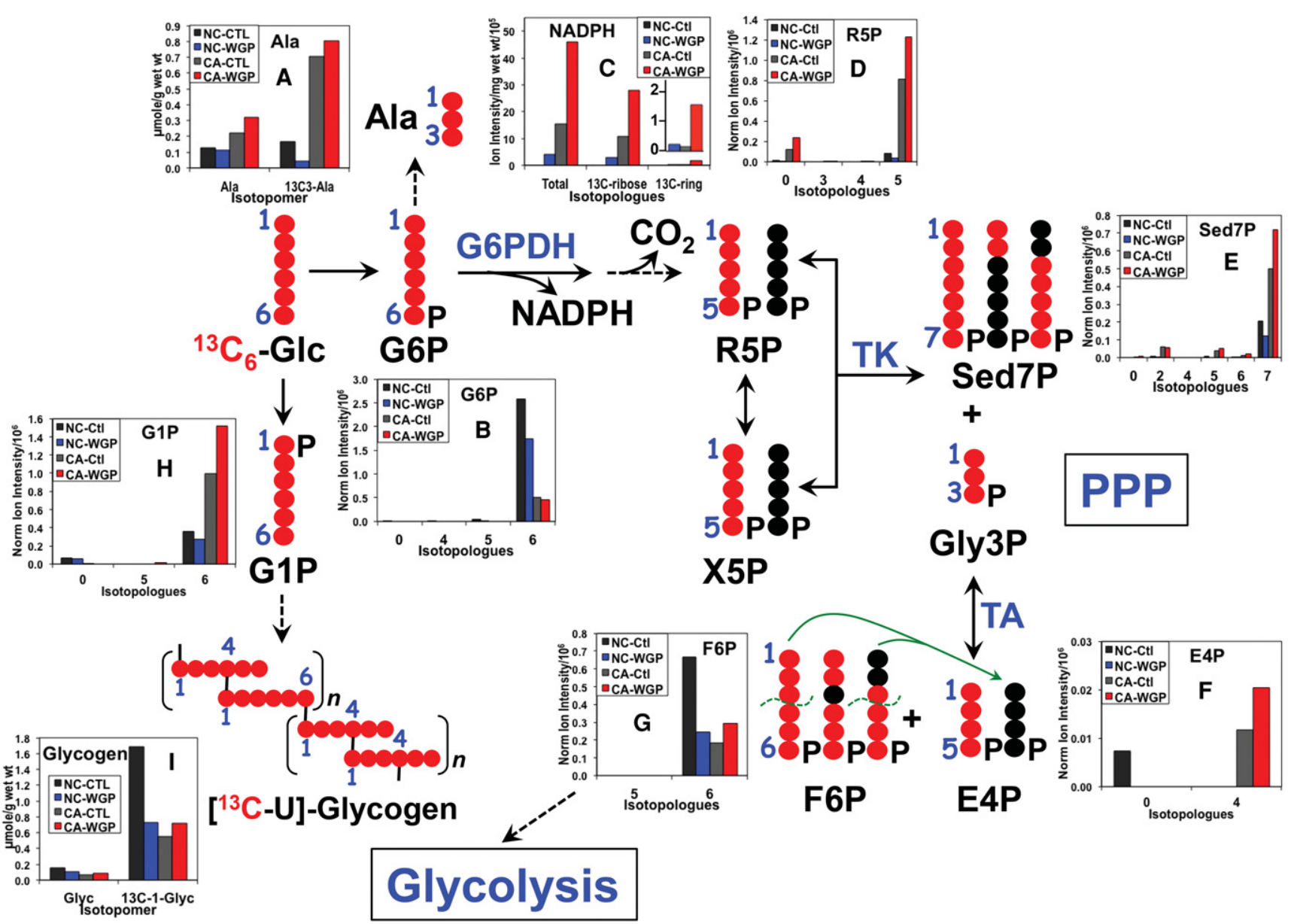

Figure 4. $\beta$-Glucan stimulates pentose phosphate pathway (PPP), NADPH production, and glycogen synthesis in UK021 CA tissue slices. PPP metabolite analysis by IC-FTMS is as described in Figure 2. NADPH was analyzed by liquid chromatography (LC)-FTMS, whereas glycogen was quantified by ${ }^{1} \mathrm{H} N M R$, as described in Methods. ${ }^{13} \mathrm{C}$-ribose enrichment in NADPH was estimated from the enrichment sum of ${ }^{13} \mathrm{C}_{5^{-}}+{ }^{13} \mathrm{C}_{10}$-isotopologues, whereas ${ }^{13} \mathrm{C}$-ring (adenine) enrichment in NADPH was derived from the enrichment sum of the remaining ${ }^{13}$ C-isotopologues (Sellers et al. 2015). $\bullet,{ }^{12} \mathrm{C}$; $\bullet,{ }^{13} C_{\text {; }}$ R5P, ribose-5-phosphate; X5P, xylulose-5phosphate; Sed7P, sedoheptulose-7-phosphate; Gly3P, glyceraldehyde-3-phosphate; E4P, erythrose-4-phosphate; F6P, fructose-6-phosphate; G6P, glucose-6-phosphate; G1P, glucose-1-phosphate; Glyc, glycogen; G6PDH, glucose-6-phosphate dehydrogenase; TK, transketolase; TA, transaldolase. The green dashed curves denote $\mathrm{C}-\mathrm{C}$ bond break in TA reaction, and the green arrows delineate the addition of the ${ }^{13} \mathrm{C}_{3^{-}}$and ${ }^{13} \mathrm{C}_{1}-3$ carbon fragment to the unlabeled E4P to form ${ }^{13} \mathrm{C}_{3}$ - and ${ }^{13} \mathrm{C}_{1}$-Sed7P, which represent contributions from the nonoxidative branch of PPP. This contribution was minimal because of the very low level of ${ }^{13} C_{3^{-}}$and ${ }^{13} C_{1^{-}}$ Sed7P species in E. Comparing WGP- versus control-treated CA tissue slices, WGP enhanced buildup of PPP-specific intermediates ${ }^{13} C_{7}-\operatorname{Sed} 7 P(E) /{ }^{13} C_{4}-E 4 P(F)$ and NADPH (product of the oxidative branch, $C$ ) was evident. This supports stimulation of the oxidative branch of PPP. Likewise, enhanced buildup of glycogen precursor ${ }^{13} \mathrm{C}_{6}-\mathrm{G} 1 \mathrm{P}(H)$ and ${ }^{13} \mathrm{C}$-glycogen $(I)$ by WGP was observed in the CA tissue slice. In contrast, PPP metabolites, NADPH, and glycogen metabolites responded negatively to WGP in the NC tissue slice.

in UK049 CA tissue slices (Fig. 3I), which suggests that the ME activity may also contribute to WGP-induced NADPH buildup in the former but not in the latter. As NADPH is the reductant for regenerating glutathione (GSH) from GSSG (the oxidized form of glutathione), the WGP effect on NADPH production can account for the buildup of unlabeled GSH in UK021 CA tissue slices ( 0 isotopologue, Fig. 2K) but not in UK049 CA tissue slices (Fig. 3K). 


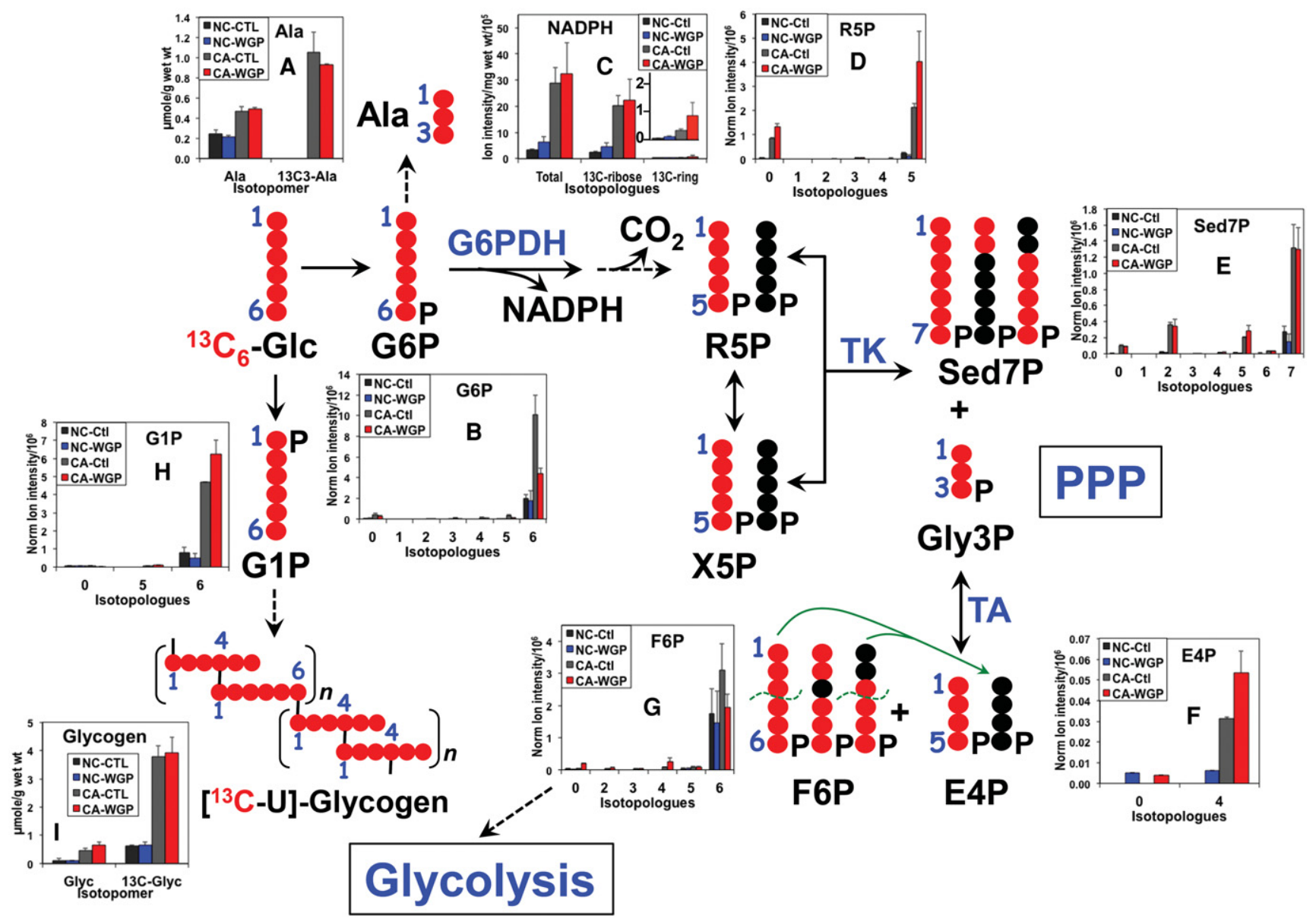

Figure 5. $\beta$-Glucan has little effect on PPP, NADPH production, and glycogen synthesis in UK049 CA tissue slices. The same analyses as in Figure 4 were performed for UK049 tissue slices. Each value was an average of two replicates with the error bars as standard error of means. No significant buildup of ${ }^{13} \mathrm{C}_{7}$-Sed7P (unique metabolite of PPP, E) or total and ${ }^{13} \mathrm{C}$-ribose containing NADPH $(C)$ was evident in CA tissue slices in response to WGP. As with the UK021 case, there was no significant presence of ${ }^{13} \mathrm{C}_{3^{-}}$and ${ }^{13} \mathrm{C}_{1}$-Sed7P in $E$. This is consistent with little effect of WGP on the oxidative branch of PPP in CA tissue slices. A small buildup of ${ }^{13} \mathrm{C}_{6}-\mathrm{G} 1 \mathrm{P}$ $(H)$ was induced by WGP in CA tissue slices but no significant accumulation of the product ${ }^{13} \mathrm{C}$-glycogen (I) was evident. NC tissues showed little response to WGP in terms of all of these metabolites. All abbreviations are as in Figure 4. $\bullet,{ }^{12} \mathrm{C} ; \bullet,{ }^{13} \mathrm{C}$.

Glycogen Synthesis Is Activated by $\beta$-Glucan in UK021 but Not in UK049 CA Tissue Slices

WGP appeared to activate the glycogen synthesis pathway in the UK021 CA tissue slice, as evidenced by the excess buildup of the labeled glycogen precursor ${ }^{13} \mathrm{C}_{6}$-glucose-1-phosphate $(\mathrm{G} 1 \mathrm{P}, \mathrm{Fig} .4 \mathrm{H})$ and the ${ }^{13} \mathrm{C}$-glycogen product when comparing WGP versus control treatments (Glyc, Fig. 4I). Although ${ }^{13} \mathrm{C}_{6}-\mathrm{G} 1 \mathrm{P}$ accumulated to a small extent in the UK049 CA tissue slices in response to WGP (Fig. $5 \mathrm{H}$ ), the ${ }^{13} \mathrm{C}$-glycogen product did not build up significantly (Fig. 5I). Mammalian macrophages have been shown to synthesize glycogen, and the glycogen content depletes during phagocytotic activity (Gudewicz 1975). Recently, exogenous glycogen was shown to stimulate the production of nitric oxide (NO) and inflammatory cytokines by murine macrophage via the Toll-like receptor 2 pathway (Kakutani et al. 2012). These data point to a role of glycogen metabolism in macrophage- 
mediated immune stimulation, such as WGP-induced iNOS expression in UK021 CA lung tissue slice (cf. Fig. 7C).

We further note that ${ }^{13} \mathrm{C}_{6}$-glucose metabolism via glycolysis, the Krebs cycle, glutathione synthesis, PPP, and/or nucleotide synthesis was enhanced in CA over NC tissue slices for both UK021 and UK049 patients, as evidenced by the excess buildup in the ${ }^{13} \mathrm{C}$-labeled metabolites of these pathways in the former tissue slices (Figs. 2-5; Supplemental Figs. S2 and S5-S6). These ex vivo metabolic differences recapitulate those of the CA versus NC tissues in vivo as we have previously reported (Sellers et al. 2015). Notably, the UK021 patient had a lower capacity for glycogen synthesis in the NC than CA tissue slices, whereas the opposite was observed for the UK049 patient (Fig. 4 I versus 5I; Supplemental Fig. S5 versus S6). Moreover, the metabolic effect of WGP on NC tissue slices was mostly opposite to that on the paired CA tissue slices for both patients, including PPP, the Krebs cycle, and GSH, Ala, and glycogen synthesis (Figs. 2-5). One notable exception was the release of ${ }^{13} \mathrm{C}_{3}$-lactate into the medium (Supplemental Fig. S2), for which both NC and CA tissue slices of UK049 responded negatively to WGP (i.e., decreased glycolytic flux in these tissues).

\section{$\beta$-Glucan Enhances Necrosis and Reduces Mitotic Index in UK021 CA Lung Tissue Slices but Not in UK049 CA Lung Tissue Slices}

We were intrigued by the above-described distinctly perturbed metabolic networks in tumor tissue slices obtained from two patient individuals and asked the question if such metabolic differences lead to different tissue pathological outcomes. We used two molecular markers, RIP-1 and PCNA, to examine the effect of WGP on tissue necrosis and mitotic index, respectively. As shown in Figure 6A, the extent of necrosis increased, whereas the mitotic index decreased in UK021 CA tissue slices in response to WGP. In contrast, UK049 CA tissue slices did not become more necrotic while exhibiting a higher mitotic index with the WGP treatment (Fig. 6B). The effect on necrosis and mitotic index elicited by WGP in UK021 CA tissue slices is unexpected based on the enhancement of glycolysis, Krebs cycle, PPP, NADPH/GSH production, and itaconate buildup by WGP (Figs. 2 and 4). Instead, it is consistent with the polarization of TAM to the M1-like phenotype (Ghesquiere et al. 2014). The necrotic response could reflect oxidative stress resulting from abnormal Krebs cycle activity. The enhanced PPP activity as well as NADPH and GSH production in UK021 (Figs. 2 and 4) but not in UK049 CA tissue slices (Figs. 3 and 5) is consistent with this notion. Moreover, an opposite relationship -that is, decreased Krebs cycle activity, GSH synthesis (Fig. 2), and necrotic response (Fig. 6A) - was noted for the UK021 NC tissue slice. Together, these data suggest that the UK021 CA lung tissue slice responds to WGP by enhancing Krebs cycle and thus oxidative stress, which in turn induces necrotic tissue injuries and antioxidant production.

The increase in mitotic index of UK049 CA tissue slices by WGP is also unexpected based on the attenuated glycolytic activity (Supplemental Fig. S2) and lack of changes in other metabolic activities observed, except for the increased synthesis of citrate (Fig. 3E). Further investigation into the citrate-mediated metabolic network is needed to better understand its connection to mitotic index.

\section{Differential Macrophage Activation May Contribute to Distinct Perturbations of Ex Vivo Tissue Metabolic Network and Injuries Induced by $\beta$-Glucan}

We then asked if TAMs in UK021 and UK049 CA lung tissue slices could contribute to the differential metabolic responses described above. Therefore, we probed TAM distribution and phenotypes after WGP treatment in the two patients' lung tissue slices. As shown in Supplemental Figure S7, both NC and CA lung tissues of UK021 maintained a higher number of $\mathrm{CD} 68^{+}$macrophages than the counterpart tissue slices of UK049 under both control and WGP treatments, as the case for their corresponding freshly resected bulk tissues 
A

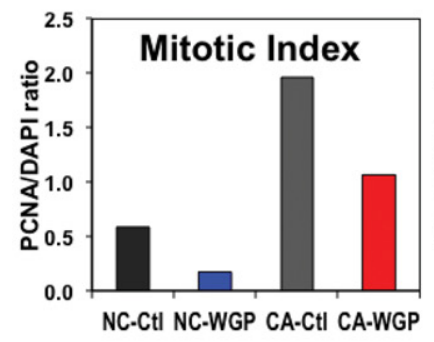

PCNA
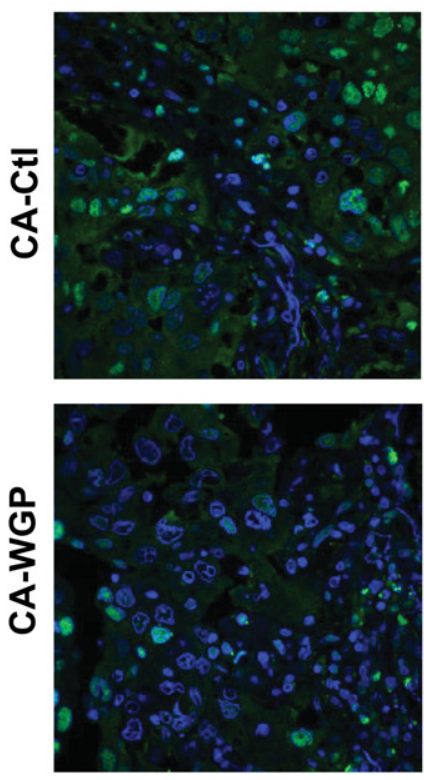

UK021

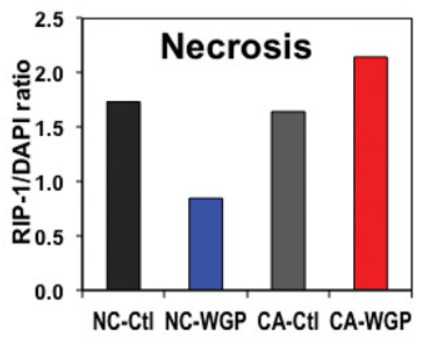

RIP-1
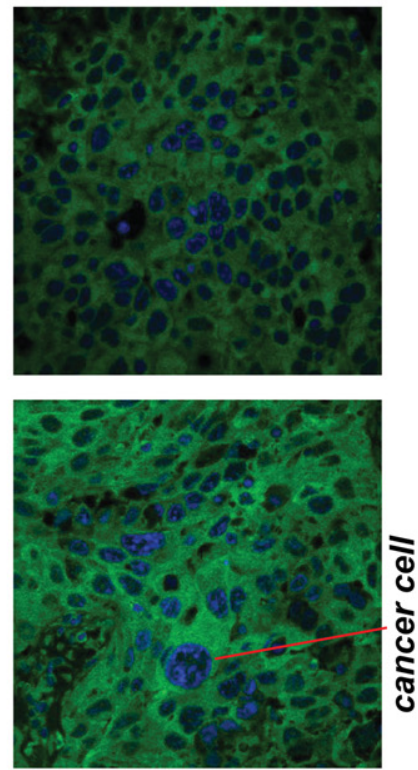

B

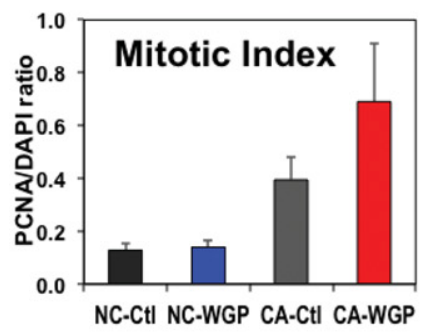

PCNA
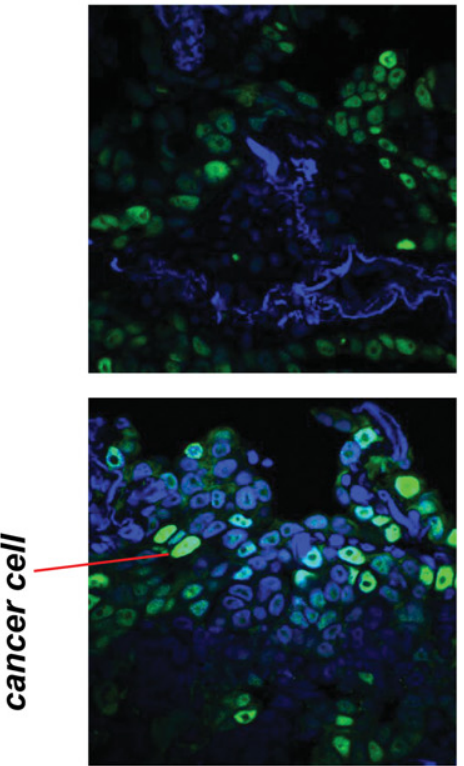

UK049

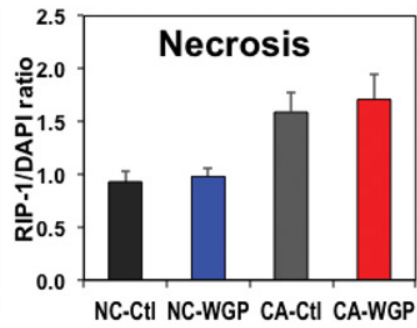

RIP-1
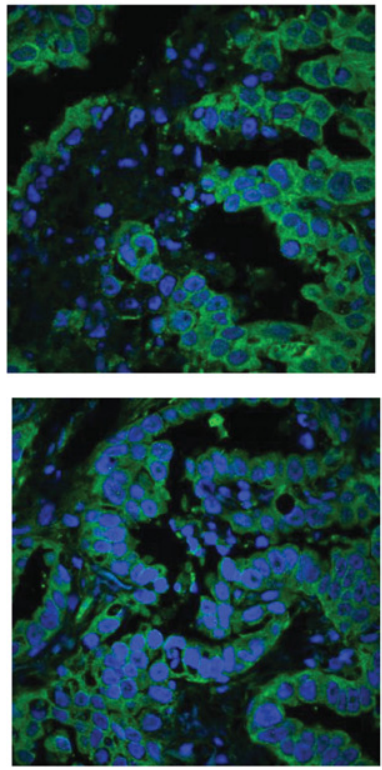

Figure 6. $\beta$-Glucan enhances necrosis and reduces proliferation potential in UK021 CA tissue slices but not in UK049 CA tissue slices. After the WGP treatment, a small portion of the tissue slices were preserved in formalin and subjected to fluorescence-based histochemical staining separately for PCNA (a mitotic index marker) and RIP-1 (a necrosis marker) (cf. green fluorescence in A and B). All PCNA and RIP-1 stained slides were also stained with DAPI for nuclei (blue fluorescence in A and B), as described in Methods. All images were acquired at 60x magnification. The green fluorescence intensity from three to seven image frames of each slide was averaged for the bar graphs in $A$ and $B$, with the error bars in $B$ representing standard error of the average of averaged fluorescence intensity from two replicate slices. The mitotic index for the UK021 CA tissue slice was reduced, along with an increase in necrosis in response to WGP (A). The mitotic index for the UK049 CA tissue slices responded positively to WGP in contrast to that for the UK021 CA tissue slice, with little change in necrosis (B). The UK021 NC tissue slices had much lower mitotic index than the CA counterpart with a negative response of necrosis to the WGP treatment (A). For the UK049 NC tissue slices, both mitotic index and extent of necrosis were lower than those in the CA counterpart with little change in either parameter in response to WGP.

(Fig. 1C,D). The expression of M1-phenotype marker iNOS was evident in CD68 ${ }^{+}$TAM and non-CD68 ${ }^{+}$cells (e.g., cancer cells) in both UK021 (Fig. 7A) and UK049 (Fig. 7B) CA tissue slices. Again, we used the iNOS/CD68 ratio as the measure of iNOS expression normalized to the abundance of $\mathrm{CD} 68^{+}$macrophages. We found that this ratio was enhanced in UK021 CA lung tissues in response to WGP but not in UK049 CA lung tissues with no change in the corresponding NC lung tissues (compare bar graphs in Fig. 7A,B). It is also interesting to note that the iNOS/CD68 ratio was much higher in UK021 than UK049 CA tissue slices 
A

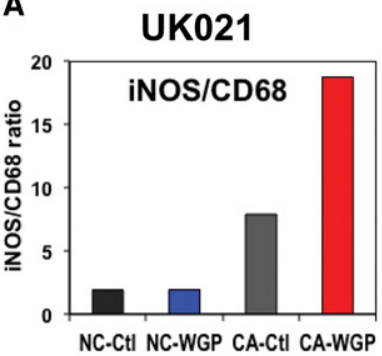

iNOS+CD68
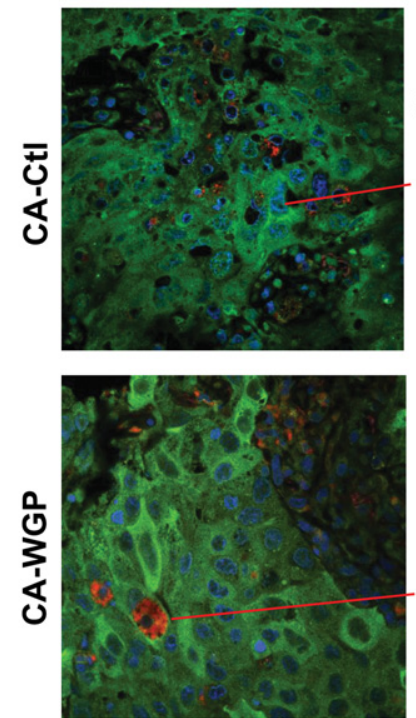

B

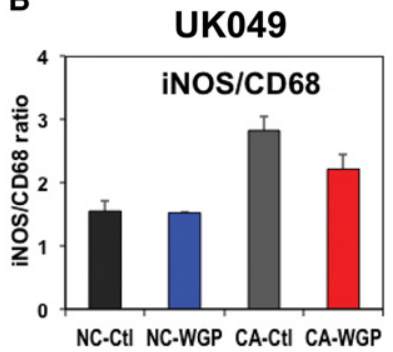

iNOS+CD68
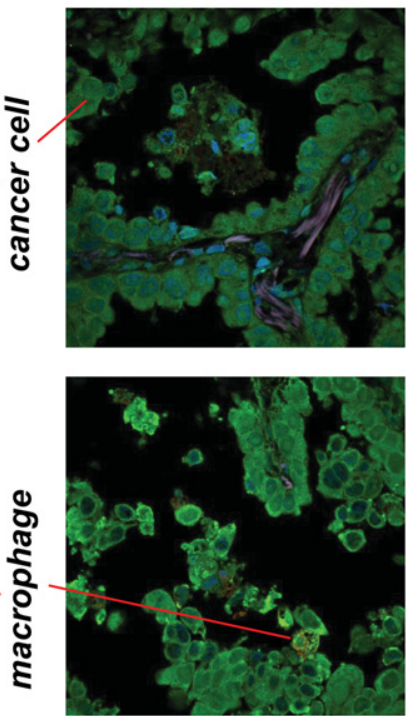

Figure 7. $\beta$-Glucan-enhanced iNOS expression in UK021 but not UK049 CA lung tissue slices. WGP treatment, tissue preservation, and immunohistochemical analysis are as in Figure 6. As in Figure 1, the green fluorescence (iNOS) was normalized to the red fluorescence (CD68) to reflect WGP-induced increase in iNOS expression relative to CD68 expression for UK021 (A) but not for UK049 (B) CA lung tissue slices.

after WGP treatment, which was opposite to the case for the corresponding bulk tissues (Fig. 1C,D). Together, these data suggested that WGP activated iNOS expression and possibly M1-like phenotype of TAM in UK021 CA tissue slices but failed to do so in UK049 CA tissue slices.

If so, WGP-induced TAM activation could underlie the activated metabolic networks described above in the UK021 CA lung tissue. iNOS expression is closely linked to NO production, which in excess can be tumoricidal (Vannini et al. 2015). We further surmise that TAM activation could contribute to the decreased mitotic index by inducing NO production via iNOS expression and production of reactive oxygen species (ROS) via the Krebs cycle, leading to necrosis (cf. Fig. 6A). Further investigations will be needed to substantiate this notion.

\section{DISCUSSION}

The two NSCLC patients UK021 and UK049 investigated had the same tumor type (adenocarcinoma) and staging ( $\mathrm{pT}_{3} \mathrm{~N}_{0} \mathrm{M}_{0}$, stage IIB) but differed in tumor grade, gender, and age 
COLD SPRING HARBOR Molecular Case Studies
$\beta$-Glucan distinctly perturbs metabolism in NSCLC tissues (cf. Table 1). As $\beta$-glucan is a known activator of macrophages, the clinical diagnosis of COPD for UK021 but not for UK049 is of particular relevance. This difference in comorbidity presumably accounted for the higher number of TAMs (Fig. 1C,D; Supplemental Fig. S1), lower mitotic index, and higher level of necrosis (Fig. 1A,B) in UK021 than in UK049 CA lung tissues. The extensive chronic inflammation could also underlie the more suppressive TAM phenotype (lower iNOS/CD68 ratio; Fig. 1C,D) in the UK021 CA lung tissue.

The abundance of TAMs as well as their more suppressive state in the UK021 CA lung tissue can be related to the metabolic responses of their cultured slices to $\beta$-glucan (WGP), which were distinct from those of the cultured UK049 CA lung tissue slices with a lot fewer but possibly more active starting TAMs. WGP activated glycolysis, the Krebs cycle, PPP, and the production of NADPH, glutathione, and glycogen in UK021 (Figs. 2 and 4; Supplemental Figs. S2 and S3) but not in UK049 CA lung tissue slices (Figs. 3 and 5; Supplemental Figs. S2 and S4). These metabolic effects reflected the response of the whole tissue, which involved the complex interactions of cancer and stromal cells in the TME. Although several of these enhanced pathways and product generation (e.g., glycolysis, Krebs cycle intermediate succinate, NADPH, and GSH) are known to be associated with cancer cell metabolism, the response to the immune modulator $\beta$-glucan is also consistent with the polarization to inflammatory or M1 phenotype of macrophages in response to microbial infection or proinflammatory cytokines (Ghesquiere et al. 2014). In addition, the activation of these metabolic networks was accompanied by the buildup of itaconate in the UK021 but not UK049 CA lung tissue slices. Itaconate has been shown to stimulate murine macrophages toward M1 phenotype (Strelko et al. 2011; Michelucci et al. 2013). Furthermore, the M1-like state of TAM induced by WGP in the UK021 CA lung tissue slice is consistent with its iNOS overexpression and increased necrosis; the latter is possibly a result of excess production of $\mathrm{NO}$ and Krebs cycle-mediated ROS.

WGP could also perturb the cancer cell metabolism in these CA tissue slices, not just macrophages. However, four lines of evidence argued against a significant contribution of activated cancer cell metabolism to the observed metabolic response of UK021 CA tissue slices. First, lung adenocarcinoma A549 cell growth was not affected by WGP (data not shown) and therefore it is unlikely that WGP activates these metabolic processes in the cancer cell population of adenocarcinoma tissue slices. Second, the extent of necrosis increased in the UK021 CA tissue, particularly in the cancer cell-rich region (Fig. 6A), which is inconsistent with activation of cancer cell metabolism in this tissue. Third, iNOS overexpression (Fig. 7A) along with necrosis elicited by WGP in the UK021 CA lung tissue slice suggest sustained and excess NO production (Vannini et al. 2015), which can lead to tumoricidal action (Liu et al. 1998), not metabolic activation. Finally, similar metabolic processes of isolated macrophages was strongly activated by WGP (Liu et al. 2015).

Thus, in this two-case NSCLC patient study, we demonstrated that ex vivo CA lung tissue slices were metabolically more active than their NC lung counterparts, which recapitulated the metabolic reprogramming in CA lung tissues observed in vivo (Sellers et al. 2015). We also showed that the macrophage-activator $\beta$-glucan reprogrammed lung CA tissue metabolism ex vivo in one NSCLC patient with COPD and abundance of TAMs (UK021) but not in the other patient (UK049) with no COPD and much less macrophage infiltration. We surmise that the observed reprogrammed networks could reflect $\beta$-glucan activation of M1 phenotype of human macrophages. As such, this study presents a unique opportunity for investigating metabolic responses of human tumor-associated macrophages to immune modulators in their native microenvironment on an individual patient basis. Further and more extensive investigations are underway with a larger cohort, which will help validate this case study in terms of the metabolic basis of the differential tumoricidal action of $\beta$-glucan among different NSCLC patients, ultimately leading to informed decision on the choice of $\beta$-glucan for individual NSCLC therapy. 
COLD SPRING HARBOR Molecular Case Studies
$\beta$-Glucan distinctly perturbs metabolism in NSCLC tissues

\section{METHODS}

\section{Human Subjects}

Patients UK021 and UK049 diagnosed with primary adenocarcinoma and eligible for surgical resection were recruited, and written consent was obtained for the collection of blood, urine, and lung tissues under the University of Kentucky approved IRB protocol (IRB 14-0288-F6A).

\section{Lung Tissue Collection, Slice Preparation, Treatment, and Extraction}

Fresh CA and surrounding NC (distal and proximal to CA) lung tissues were collected in the operating room within 5 min of surgical resection, a portion of which was immediately flash-frozen in liquid $\mathrm{N}_{2}$ for metabolite analysis and a second portion was preserved in $4 \%$ buffered formalin (Fisher Scientific). The remaining tissues were thinly sliced by the surgeon at 0.7- to 1-mm thickness with wet weights of 8-20 mg for UK021 tissue slices and 14-29 $\mathrm{mg}$ for UK049 tissue slices. All tissue slices were incubated in glucose and Gln-free DMEM media (Sigma-Aldrich) supplemented with $0.45 \%$ unlabeled or ${ }^{13} \mathrm{C}_{6}$-glucose (Cambridge losotope Laboratories), $2 \mathrm{mM}$ Gln, 10\% dialyzed fetal bovine serum, $50 \mathrm{U} / \mathrm{mL}$ penicillin, and $50 \mu \mathrm{g} / \mathrm{mL}$ streptomycin (Fisher Scientific) for $24 \mathrm{~h}$ at $37^{\circ} \mathrm{C} / 5 \% \mathrm{CO}_{2}$ with gentle rocking to facilitate nutrient supplies and waste product mixing (Sellers et al. 2015; Fan et al. 2016). One half of the cultured tissue slices also contained $100 \mu \mathrm{g} / \mathrm{mL}$ WGP $\beta$-glucan (Biothera) in sterile phosphate-buffered saline (PBS), whereas the other half had none to serve as controls. Culture media were sampled at 0,9 or 11 , and $24 \mathrm{~h}$ of incubation. At the end of incubation, tissue slices were quickly rinsed in cold PBS three times to remove medium components, blotted dry, weighed on a four-place balance for wet weight, and flash-frozen in liquid $\mathrm{N}_{2}$.

The frozen tissues were then homogenized in $60 \%$ cold $\mathrm{CH}_{3} \mathrm{CN}$ in a ball mill (Precellys24, Bertin Technologies) for denaturing proteins and optimizing extraction. Polar metabolites were extracted by the solvent partitioning method with a final $\mathrm{CH}_{3} \mathrm{CN}: \mathrm{H}_{2} \mathrm{O}: \mathrm{CHCl}_{3}$ $(2: 1.5: 1, v / v)$ ratio, as described previously (Fan 2012). The polar extracts were lyophilized before reconstitution in $50 \% \mathrm{D}_{2} \mathrm{O}$ for NMR analysis or in $\mathrm{H}_{2} \mathrm{O}$ for IC-FTMS analysis. The culture media were deproteinated in $80 \%$ acetone at $-20^{\circ} \mathrm{C}$ for $0.5 \mathrm{~h}$ before centrifugation, lyophilization, and reconsititution in $50 \% \mathrm{D}_{2} \mathrm{O}$ for ${ }^{1} \mathrm{H}$ NMR analysis.

\section{Histochemical and Image Analysis}

The tissue specimens were formalin-fixed and paraffin-embedded, sliced as 4- $\mu \mathrm{m}$ thick tissue sections, deparaffinized in Xylene Substitute (A5597, Sigma-Aldrich), and rehydrated through graded alcohols. Antigen retrieval was carried out using $10 \mathrm{mM}$ sodium citrate buffer ( $\mathrm{pH}$ 6.0) in a microwave (heated to boiling, maintained at a subboiling temperature for $10 \mathrm{~min}$, and then cooled at room temperature for $30 \mathrm{~min}$ ). Methanol permeabilization was performed for PCNA staining by incubating tissue sections in ice-cold 100\% methanol at $-20^{\circ} \mathrm{C}$ for $10 \mathrm{~min}$ followed by PBS rinse for $5 \mathrm{~min}$. Nonspecific binding was blocked with $10 \%$ appropriate host serum, 3\% BSA, and 0.3\% Triton X-100 in 1 $\times$ PBS at room temperature for $1 \mathrm{~h}$, followed by incubation with primary antibodies at $4^{\circ} \mathrm{C}$ for overnight. Tissue sections were then rinsed three times with PBS for 5 min each before incubation with fluorescent-conjugated secondary antibodies in the dark at room temperature for $1 \mathrm{~h}$, followed by three rinses with PBS for 5 min each.

Primary antibodies used were as follows: PCNA (D3H8P) XP Rabbit mAb (1:800) and RIP1 (D94C12) XP Rabbit mAb (1:100, Cell Signaling Technology); CD68 (KP1) (1:200, mouse monoclonal, Santa Cruz Biotechnology); iNOS (1:200, rabbit polyclonal PA3-030A, ThermoFisher Scientific). Secondary antibodies used were as follows: goat anti-rabbit lgG $(\mathrm{H}+\mathrm{L})$ Alexa Fluor 488 (1:100), donkey anti-mouse IgG Alexa Fluor 594 (undiluted); rabbit anti-rat lgG $(\mathrm{H}+\mathrm{L})$ Alexa Fluor 594 (1:200) from Thermo Fisher Scientific; goat anti-mouse 
COLD SPRING HARBOR Molecular Case Studies
$\beta$-Glucan distinctly perturbs metabolism in NSCLC tissues
IgG H\&L Alexa Fluor 488 (1:200) (Abcam). The antibody dilution buffer was 1\% BSA and 0.3\% Triton $\mathrm{X}-100$ in $1 \times$ PBS.

Stained slides were mounted in ProLong Gold Antifade Mountant with DAPI (P-36931, Thermo Fisher Scientific) and fluorescent images were acquired using a laser scanning confocal microscope Olympus FluoView FV1000 with a 60x oil immersion lens (UPLSAPO 60XO).

Gomori Trichrome Staining was performed using Richard-Allan Scientific Gomori Trichrome (Blue Collagen) (87020, Thermo Scientific) following the manufacturer's standard staining protocol. The collagen fibers were stained blue, the cytoplasm and muscle fibers were stained red, and the nuclei were stained dark blue-to-black. Slides were scanned using an Aperio ePathology scanner under a $20 \times$ objective and viewed by Aperio ImageScope software.

For image quantification, positively labeled cells were counted in at least three $217 \times$ $212-\mu \mathrm{m}$ fields from the selected lung slices. For all stained slides, three to eight image frames were captured from each color channel at 12-bit digital resolution using the appropriate fluorescence filter set, under identical exposure and magnification settings. The image frames were then analyzed using the ImageJ program (National Institutes of Health). Region of interest (ROI) of each image frame was quantified by thresholding individual frames and using the function "Analyze particles" to calculate the percentage of the image area exceeding the set threshold. This value was averaged over multiple frames before the ratio of the "green" (PCNA, RIP-1, or iNOS) or "red" (CD68) fluorescence to the "blue" DAPI fluorescence was calculated.

\section{NMR Analysis}

The polar extracts were analyzed in 1.7-mm tubes on an automated 14.1 T NMR spectrometer equipped with a 3-mm HCN cold probe (Agilent Technologies). ${ }^{1} \mathrm{H}$ NMR data were acquired using a simple one-pulse method with a $90^{\circ}$ observe pulse, water presaturation, 6-sec interpulse delay, and 512 transients. ${ }^{13} \mathrm{C}$-edited ${ }^{1} \mathrm{H}$ heteronuclear single quantum coherence (HSQC) spectra were acquired with $90^{\circ}$ observe pulse, 2-sec interpulse delay, and an adiabatic ${ }^{1} \mathrm{H}$ decoupling scheme. The ${ }^{1} \mathrm{H}$ resonance intensities in $1 \mathrm{D}^{1} \mathrm{H}$ and $\mathrm{HSOC}$ spectra were quantified by using the peak deconvolution routine of the MesReNova software and calibrated against the peak intensity of the methyl resonance of $d_{6}$-2,2-dimethyl-2-silapentane-5sulfonate (DSS) (an internal standard added at $27.5 \mathrm{nmol}$ ) for $1 \mathrm{D}^{1} \mathrm{H}$ or that of the methyl resonance of lactate (quantified from 1D ${ }^{1} \mathrm{H}$ spectra) for 1D HSOC.

\section{Ion Chromatography-Mass Spectrometric Analysis}

Polar extracts were reconstituted in ultrapure deionized water (EMD Millipore) in a volume based on tissue wet weight. All analyses were performed on a Dionex ICS-5000+ ion chromatography interfaced to a Thermo Fusion Orbitrap Tribrid mass spectrometer (IC-FTMS) (Thermo Fisher Scientific). lon chromatography (Wang et al. 2014) was performed using an lonPac AS11-HC-4 $\mu \mathrm{m}$ RFIC\&HPIC $(2 \times 250 \mathrm{~mm})$ column and an lonPac AG11-HC-4 $\mu \mathrm{m}$ guard column $(2 \times 50 \mathrm{~mm})$. The column flow rate was kept at $0.38 \mathrm{~mL} / \mathrm{min}$ with column temperature at $35^{\circ} \mathrm{C}$ and $0.06 \mathrm{~mL} / \mathrm{min}$ methanol added postcolumn as a makeup solvent to aid vaporization in the heated electrospray ionization (HESI) unit. The HESI vaporizer temperature was $400^{\circ} \mathrm{C}$ with sheath gas set at $35 \mathrm{Arb}$ and auxiliary nitrogen flow at $4 \mathrm{Arb}$. The column was initially equilibrated for 8 min with $1 \mathrm{mM} \mathrm{KOH}$, and then followed by $1 \mathrm{mM} \mathrm{KOH}$ for 2 min after $5 \mu \mathrm{L}$ of sample was injected. The $\mathrm{KOH}$ gradient program used to elute samples included ramping up to 40 $\mathrm{mM} \mathrm{KOH}$ from 2 to $25 \mathrm{~min}$, and to $100 \mathrm{mM}$ from 25 to $39.1 \mathrm{~min}$, at $100 \mathrm{mM}$ to $50 \mathrm{~min}$, and ramping down to $1 \mathrm{mM} \mathrm{KOH}$ at $50.1 \mathrm{~min}$ and at $1 \mathrm{mM} \mathrm{KOH}$ to $52.5 \mathrm{~min}$. $\mathrm{KOH}$ suppression was achieved with a Dionex AERS $5002 \mathrm{~mm}$ suppressor with an external AXP pump supplying regenerant at a flow rate of $0.75 \mathrm{~mL} / \mathrm{min}$ and injected into the Orbitrap mass spectrometer 


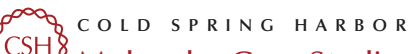
Molecular Case Studies
$\beta$-Glucan distinctly perturbs metabolism in NSCLC tissues via HESI. Mass spectra were recorded at a resolution of 450,000 (achieving a resolution of $\sim 360,000$ at $400 \mathrm{~m} / \mathrm{z}$ ) from 50 to $750 \mathrm{~m} / \mathrm{z}$ mass scan range, with detection in the negative ion mode voltage using the following settings: $\mathrm{HESI}=2800 \mathrm{~V}$; ion transfer tube temperature $=300^{\circ} \mathrm{C}$; automatic gain control $(\mathrm{AGC})=2 \times 10^{5}$; maximal injection time $=100 \mathrm{msec}$. Peak areas were integrated and exported to Excel via the Thermo TraceFinder (version 3.3) software package. Peak areas were corrected for natural abundance as previously described (Moseley 2010).

\section{ADDITIONAL INFORMATION}

\section{Data Deposition and Access}

The raw analytical data and relevant metadata have been deposited at the Metabolomics Consortium Data Repository and Coordinating Center (DRCC; http://www. metabolomicsworkbench.org/data/index.php) under project number PR000292.

\section{Ethics Statement}

Written consent was obtained for the collection of human tissue, blood, and urine samples under an IRB approved protocol (IRB 14-0288-F6A) at the University of Kentucky.

\section{Acknowledgments}

We thank Teresa Cassel, Yan Zhang, Penghui Lin, Ramon Sun, Timothy Scott, Anh-Thu Le, and Maria Scavo for assistance on the collection, experimentation, processing, and extraction of human tissue slices and media; we also thank Penghui Lin for assistance in the medium NMR analysis.

\section{Author Contributions}

T.W.-M.F. designed the experiments, collected samples, analyzed/interpreted data, and wrote the manuscript; A.N.L. designed experiments, collected samples, and contributed to the manuscript writing; M.O.W., Q.S., and R.M.H. performed IC-FTMS analysis and contributed to the manuscript writing; H.S. and J.T.-C. performed histochemical analysis and contributed to the manuscript writing; and A.M. and J.T.M. contributed to experimental design, performed the lung surgeries, and procured thin tissue slices for ex vivo studies.

\section{Funding}

This work was supported in part by the National Institutes of Health (NIH) P01 CA16322301A1, NIH 1R21ES025669-01, NIH 1U24DK097215-01A1, the Edith D. Gardner Endowed Chair (to T.W.-M.F.), and the Carmen L. Buck endowed chair (to A.N.L.). NMR and mass spectrometry data were recorded at the Center for Environmental and Systems Biochemistry supported by the University of Kentucky and by National Cancer Institute (NCl) Cancer Center Support Grant (P30 CA177558).

\section{REFERENCES}

Belenky P, Bogan KL, Brenner C. 2007. NAD ${ }^{+}$metabolism in health and disease. Trends Biochem Sci 32: 12-19.

Benoit M, Desnues B, Mege JL. 2008. Macrophage polarization in bacterial infections. J Immunol 181: 3733-3739. 
Bonuccelli G, Whitaker-Menezes D, Castello-Cros R, Pavlides S, Pestell RG, Fatatis A, Witkiewicz AK, Heiden MG, Migneco G, Chiavarina B, et al. 2010. The reverse Warburg effect: glycolysis inhibitors prevent the tumor promoting effects of caveolin-1 deficient cancer associated fibroblasts. Cell Cycle 9: 1960-1971.

Caneba CA, Yang L, Baddour J, Curtis R, Win J, Hartig S, Marini J, Nagrath D. 2014. Nitric oxide is a positive regulator of the Warburg effect in ovarian cancer cells. Cell Death Dis 5: e1302.

Cheng T, Sudderth J, Yang C, Mullen AR, Jin ES, Mates JM, DeBerardinis RJ. 2011. Pyruvate carboxylase is required for glutamine-independent growth of tumor cells. Proc Natl Acad Sci 108: 8674-8679.

Dang L, White DW, Gross S, Bennett BD, Bittinger MA, Driggers EM, Fantin VR, Jang HG, Jin S, Keenan MC, et al. 2009. Cancer-associated IDH1 mutations produce 2-hydroxyglutarate. Nature 462: 739-744.

Fan TW-M. 2012. Sample preparation for metabolomics investigation. In The handbook of metabolomics: pathway and flux analysis, methods in pharmacology and toxicology (ed. Fan TW-M, Lane AN, Higashi RM), pp. 7-27. Springer Science, New York.

Fan TW, Lane AN, Higashi RM, Farag MA, Gao H, Bousamra M, Miller DM. 2009. Altered regulation of metabolic pathways in human lung cancer discerned by ${ }^{13} \mathrm{C}$ stable isotope-resolved metabolomics (SIRM). Mol Cancer 8: 41.

Fan TW, Lane AN, Higashi RM. 2016. Stable isotope resolved metabolomics studies in ex vivo tissue slices. Bioprotocol 6: e1730.

Faubert B, Boily G, Izreig S, Griss T, Samborska B, Dong Z, Dupuy F, Chambers C, Fuerth BJ, Viollet B, et al. 2013. AMPK is a negative regulator of the Warburg effect and suppresses tumor growth in vivo. Cell Metab 17: 113-124.

Ghesquiere B, Wong BW, Kuchnio A, Carmeliet P. 2014. Metabolism of stromal and immune cells in health and disease. Nature 511: 167-176.

Graham DB, Becker CE, Doan A, Goel G, Villablanca EJ, Knights D, Mok A, Ng AC, Doench JG, Root DE, et al. 2015. Functional genomics identifies negative regulatory nodes controlling phagocyte oxidative burst. Nat Commun 6: 7838 .

Gudewicz PW. 1975. Mechanisms and regulation of macrophage glycogen metabolism. In Physiology, p. 114 Loyola University Chicago, Chicago, IL.

Guillaumond F, Leca J, Olivares O, Lavaut MN, Vidal N, Berthezene P, Dusetti NJ, Loncle C, Calvo E, Turrini O, et al. 2013. Strengthened glycolysis under hypoxia supports tumor symbiosis and hexosamine biosynthesis in pancreatic adenocarcinoma. Proc Natl Acad Sci 110: 3919-3924.

Hanahan D, Weinberg RA. 2011. Hallmarks of cancer: the next generation. Cell 144: 646-674.

Ho P-C, Bihuniak Jessica D, Macintyre Andrew N, Staron M, Liu X, Amezquita R, Tsui Y-C, Cui G, Micevic G, Perales Jose C, et al. 2015. Phosphoenolpyruvate is a metabolic checkpoint of anti-tumor T cell responses. Cell 162: 1217-1228.

Kakutani R, Adachi Y, Takata H, Kuriki T, Ohno N. 2012. Essential role of Toll-like receptor 2 in macrophage activation by glycogen. Glycobiology 22: 146-159.

Kim D, Fiske BP, Birsoy K, Freinkman E, Kami K, Possemato RL, Chudnovsky Y, Pacold ME, Chen WW Cantor JR, et al. 2015. SHMT2 drives glioma cell survival in ischaemia but imposes a dependence on glycine clearance. Nature 520: 363-367.

Le A, Lane AN, Hamaker M, Bose S, Gouw A, Barbi J, Tsukamoto T, Rojas CJ, Slusher BS, Zhang H, et al. 2012. Glucose-independent glutamine metabolism via TCA cycling for proliferation and survival in B cells. Cell Metab 15: 110-121.

Leithner K, Wohlkoenig C, Stacher E, Lindenmann J, Hofmann NA, Galle B, Guelly C, Quehenberger F, Stiegler P, Smolle-Juttner FM, et al. 2014. Hypoxia increases membrane metallo-endopeptidase expression in a novel lung cancer ex vivo model-role of tumor stroma cells. BMC Cancer 14: 40.

Liu CY, Wang CH, Chen TC, Lin HC, Yu CT, Kuo HP. 1998. Increased level of exhaled nitric oxide and upregulation of inducible nitric oxide synthase in patients with primary lung cancer. $\mathrm{Br} \mathrm{J}$ Cancer 78: 534-541.

Liu M, Luo F, Ding C, Albeituni S, Hu X, Ma Y, Cai Y, McNally L, Sanders MA, Jain D, et al. 2015. Dectin-1 activation by a natural product $\beta$-glucan converts immunosuppressive macrophages into an M1-like phenotype. J Immunol 195: 5055-5065.

Maher EA, Marin-Valencia I, Bachoo RM, Mashimo T, Raisanen J, Hatanpaa KJ, Jindal A, Jeffrey FM, Choi C, Madden C, et al. 2012. Metabolism of $\left[\mathrm{U}-{ }^{13} \mathrm{C}\right]$ glucose in human brain tumors in vivo. NMR Biomed 25: 1234-1244.

Michelucci A, Cordes T, Ghelfi J, Pailot A, Reiling N, Goldmann O, Binz T, Wegner A, Tallam A, Rausell A, et al. 2013. Immune-responsive gene 1 protein links metabolism to immunity by catalyzing itaconic acid production. Proc Natl Acad Sci 110: 7820-7825.

Moseley H. 2010. Correcting for the effects of natural abundance in stable isotope resolved metabolomics experiments involving ultra-high resolution mass spectrometry. BMC Bioinformatics 11: 139 
Mullen AR, Wheaton WW, Jin ES, Chen PH, Sullivan LB, Cheng T, Yang Y, Linehan WM, Chandel NS, DeBerardinis RJ. 2012. Reductive carboxylation supports growth in tumour cells with defective mitochondria. Nature 481: 385-388.

Muller AJ, Prendergast GC. 2007. Indoleamine 2,3-dioxygenase in immune suppression and cancer. Curr Cancer Drug Targets 7: 31-40.

Nomura DK, Long JZ, Niessen S, Hoover HS, Ng SW, Cravatt BF. 2010. Monoacylglycerol lipase regulates a fatty acid network that promotes cancer pathogenesis. Cell 140: 49-61.

Ohri CM, Shikotra A, Green RH, Waller DA, Bradding P. 2009. Macrophages within NSCLC tumour islets are predominantly of a cytotoxic M1 phenotype associated with extended survival. Eur Respir J 33: 118-126.

Ohri CM, Shikotra A, Green RH, Waller DA, Bradding P. 2011. The tissue microlocalisation and cellular expression of CD163, VEGF, HLA-DR, iNOS, and MRP 8/14 is correlated to clinical outcome in NSCLC. PLoS One 6: e21874.

Rodríguez-Prados J-C, Través PG, Cuenca J, Rico D, Aragonés J, Martín-Sanz P, Cascante M, Boscá L. 2010. Substrate fate in activated macrophages: a comparison between innate, classic, and alternative activation. J Immunol 185: 605-614.

Sellers K, Fox MP, Bousamra M II, Slone SP, Higashi RM, Miller DM, Wang Y, Yan J, Yuneva MO, Deshpande R, et al. 2015. Pyruvate carboxylase is critical for non-small-cell lung cancer proliferation. J Clin Invest 125: 687-698.

Son J, Lyssiotis CA, Ying H, Wang X, Hua S, Ligorio M, Perera RM, Ferrone CR, Mullarky E, Shyh-Chang N, et al. 2013. Glutamine supports pancreatic cancer growth through a KRAS-regulated metabolic pathway. Nature 496: 101-105.

Sonveaux P, Vegran F, Schroeder T, Wergin MC, Verrax J, Rabbani ZN, De Saedeleer CJ, Kennedy KM, Diepart C, Jordan BF, et al. 2008. Targeting lactate-fueled respiration selectively kills hypoxic tumor cells in mice. J Clin Invest 118: 3930-3942.

Stern R, Shuster S, Neudecker BA, Formby B. 2002. Lactate stimulates fibroblast expression of hyaluronan and CD44: the Warburg effect revisited. Exp Cell Res 276: 24-31.

Strelko CL, Lu W, Dufort FJ, Seyfried TN, Chiles TC, Rabinowitz JD, Roberts MF. 2011. Itaconic acid is a mammalian metabolite induced during macrophage activation. J Am Chem Soc 133: 16386-16389.

Tannahill GM, Curtis AM, Adamik J, Palsson-McDermott EM, McGettrick AF, Goel G, Frezza C, Bernard NJ, Kelly B, Foley $\mathrm{NH}$, et al. 2013. Succinate is an inflammatory signal that induces IL-1 $\beta$ through HIF-1 $\alpha$. Nature 496: 238-242.

Thayanithy V, Babatunde V, Dickson EL, Wong P, Oh S, Ke X, Barlas A, Fujisawa S, Romin Y, Moreira AL, et al. 2014. Tumor exosomes induce tunneling nanotubes in lipid raft-enriched regions of human mesothelioma cells. Exp Cell Res 323: 178-188.

Vannini F, Kashfi K, Nath N. 2015. The dual role of iNOS in cancer. Redox Biol 6: 334-343.

Walenta S, Schroeder T, Mueller-Klieser W. 2004. Lactate in solid malignant tumors: potential basis of a metabolic classification in clinical oncology. Curr Med Chem 11: 2195-2204.

Wang J, Christison TT, Misuno K, Lopez L, Huhmer AF, Huang Y, Hu S. 2014. Metabolomic profiling of anionic metabolites in head and neck cancer cells by capillary ion chromatography with orbitrap mass spectrometry. Anal Chem 86: 5116-5124.

Warburg O. 1924. Is the respiration of cancer cells normal? Biochem Zeitschr 51

Warburg O. 1956. On the origin of cancer cells. Science 123: 309-314.

Wysoczynski M, Ratajczak MZ. 2009. Lung cancer secreted microvesicles: underappreciated modulators of microenvironment in expanding tumors. Int J Cancer 125: 1595-1603.

Xie H, Hanai JI, Ren JG, Kats L, Burgess K, Bhargava P, Signoretti S, Billiard J, Duffy KJ, Grant A, et al. 2014. Targeting lactate dehydrogenase-A inhibits tumorigenesis and tumor progression in mouse models of lung cancer and impacts tumor-initiating cells. Cell Metab 19: 1-15.

Yuneva M, Zamboni N, Oefner P, Sachidanandam R, Lazebnik Y. 2007. Deficiency in glutamine but not glucose induces MYC-dependent apoptosis in human cells. J Cell Biol 178: 93-105.

Zamanakou M, Germenis AE, Karanikas V. 2007. Tumor immune escape mediated by indoleamine 2,3-dioxygenase. Immunol Lett 111: 69-75. 


\section{COLD SPRING HARBOR Molecular Case Studies}

\section{Distinctly perturbed metabolic networks underlie differential tumor tissue damages induced by immune modulator $\beta$-glucan in a two-case ex vivo non-small-cell lung cancer study}

Teresa W.-M. Fan, Marc O. Warmoes, Quushi Sun, et al.

Cold Spring Harb Mol Case Stud 2016, 2: a000893 originally published online May 10, 2016

Access the most recent version at doi: $10.1101 / \mathrm{mcs} . a 000893$

Supplementary
Material
C1 1

References This article cites 44 articles, 10 of which can be accessed free at:

http://molecularcasestudies.cshlp.org/content/2/4/a000893.full.html\#ref-list-1

License This article is distributed under the terms of the Creative Commons

Attribution-NonCommercial License, which permits reuse and redistribution, except for commercial purposes, provided that the original author and source are credited.

Email Alerting Receive free email alerts when new articles cite this article - sign up in the box at the Service top right corner of the article or click here. 